\title{
Sensory factors in eating behavior
}

\author{
LINDA M. BARTOSHUK \\ Yale University School of Medicine, New Haven, Connecticut
}

\begin{abstract}
Before foods or fluids can affect behavior, they must be sensed. Olfaction, touch, temperature, and pain (e.g., chili peppers) are all sensations associated with food. Taste appears to be tuned to nutrients. Sugars are sweet, $\mathrm{NaCl}$ is salty, and many poisons are bitter. Olfaction, on the other hand, appears to be organized to identify foods holistically (e.g., bacon, pizza, peanut butter, etc.) rather than to identify the nutrients within them. The roles of the other senses in food perception are less clear. Some differences in the ability to taste and smell are genetic, age changes taste and smell differentially (age affects smell much more than taste), and pathology, disease, and treatments for disease may affect taste and smell. Species differences in taste and smell place limitations on animal models. Sensory studies have an important role in studies of eating behavior.
\end{abstract}

\section{MODALITIES THAT SENSE FOOD}

All of the sensory modalities contribute to our appreciation of foods and beverages. Vision contributes via the appearance of foods and audition contributes via the sounds (e.g., crunchiness) associated with some foods; however, these sensations do not arise from contact with the oral and nasal cavities. The sensory qualities evoked by contact with foods and beverages are taste, olfaction, touch, temperature, and pain. The roles of these modalities are sometimes misunderstood partly because we lack appropriate names for the sensations. For example, when food is placed in the mouth, it contacts the tongue and the roof of the mouth, evoking taste sensations from gustatory receptors. The volatiles from the food travel inside the mouth, up the rear of the oral cavity into the nasal cavity, and contact the olfactory receptors. The combination of taste and olfaction is called flavor. Since taste and smell are both stimulated during eating, we should not say we "taste" food; rather, we should say that we "flavor" food. Note, however, that the wrong meaning is conveyed. To flavor food means to add flavor to food. There is no verb that means to perceive flavor in food. This is probably not just a linguistic oversight. There are sensory reasons, to be discussed below, why we use the word taste to convey the perception of flavor. The individual modalities are discussed below.

\section{Temperature}

Thermal receptors in the oral cavity contribute to the perception of foods. One function of the thermal sensations is to protect the oral cavity from thermal damage, but thermal sensations obviously play a more complex role in our appreciation of foods. For example, Cines and

This research was supported by a grant from the National Institutes of Health (DC 283). Requests for reprints should be addressed to the author at Yale University School of Medicine, Department of Surgery (Otolaryngology), 333 Cedar St., P.O. Box 3333, New Haven, CT 06510.
Rozin (1982) found only a weak association between a liking for hot coffee beverage and a liking for coffee flavor. In some cases, the choice of temperature may have a sensory origin. For example, coffee will have a more intense flavor when hot because the concentration of volatiles increases with temperature. In other cases, the preferred temperature may simply be a learned preference based on family or cultural practices.

\section{Pain}

Pain sensations play a somewhat puzzling role in oral perception. Obviously, the pain sense helps prevent damage to oral tissues from teeth and from thermally or chemically dangerous stimuli. However, this does not explain why we seek out oral pain from substances like chili peppers. Rozin and Schiller (1980) list a number of explanations that have been proposed for the liking of chili pepper. One very interesting possibility is suggested by the fact that the preference for chili pepper is essentially a human phenomenon; animals appear to acquire this liking only through a close relationship with humans (Rozin \& Kennel, 1983). Chili pepper ingestion may be an example of "thrill-seeking" behavior, where people enjoy being exposed to "constrained risks."

\section{Touch}

Touch has two major functions in the perception of foods. First, the texture of foods is perceived via the sense of touch. Human subjects not only show preferences for particular textures (e.g., the smoothness of puddings) but also show aversions to some textures (e.g., the stringiness of liver). Since texture preferences and aversions appear to be idiosyncratic, they are probably acquired through learning.

Touch plays a second role in the perception of foods: It localizes taste and, probably, olfaction. The touch localization of taste can be demonstrated by "painting" solutions on the tongue with a Q-tip. The taste receptors are more densely packed at the tip of the tongue than on either 
side. If a taste solution is painted from the side to the tip, the taste intensity grows as the Q-tip moves into the area with more receptors. However, if the path is reversed and the taste solution is painted from the tip to the side, the taste intensity does not diminish as expected. Rather, the strong taste from the tip seems to fill the area touched (Bartoshuk et al., 1987). We are currently doing a series of studies to determine other properties of such taste illusions. So far, we have found that if a taste solution is painted from one side to the other, the solution is initially weak, grows as the Q-tip approaches the tip, and remains intense as the Q-tip proceeds to the second side (Todrank \& Bartoshuk, 1991). If a taste solution is painted from a circumvallate papilla on the rear of the tongue, the taste will follow the Q-tip across an area with no receptors and will even cross the midline (Green \& Bartoshuk, 1991). Taste on the front of the tongue can be temporarily abolished by injecting anesthetic behind the ear drum (where it encounters the chorda tympani taste nerve). This does not abolish touch sensations. As long as touch is intact, taste will follow a Q-tip into an area where taste is anesthetized. On the other hand, dental anesthesia (mandibular block) abolishes both taste and touch. In this case, only very weak taste sensations follow the Q-tip (Lehman, 1991). Rozin (personal communication, 1989) has shown that for at least some subjects, a similar illusion occurs for olfaction. He asked subjects to chew a tasteless, odorless gum. At intervals, he pumped chocolate volatiles into the mouth through a small tube. To the subject, the gum seemed to be the source of the chocolateits flavor flickered on and off.

Green (1977) has shown that thermal sensations of warmth and coolness are localized by touch. For example, if two cold coins are touched by the index and ring fingers while the finger between them touches a body temperature coin, all three coins will feel cold.

\section{Taste}

Early lists of taste sensations sound strange to the modern ear. For example, over two thousand years ago, Aristotle listed the expected sweet, salty, sour, and bitter, but he also added astringent, pungent, and harsh. Later lists added even more taste qualities, but in 1825 , Horn argued that many of these qualities actually belonged to other modalities. He favored sweet, salty, sour, bitter, and alkaline as the taste qualities. Both alkaline and metallic were debated at the end of the 19th century and most authorities concluded that alkaline and metallic were fusions of several qualities. This left the "four basic tastes" of the textbooks (see Bartoshuk, 1978, for a discussion). There is still debate about whether or not there may be other taste qualities not encompassed by the basic four; however, no contender for an additional taste quality has succeeded in gaining wide acceptance.

\section{Olfaction}

Lists of olfactory sensations have a history very different from lists of taste sensations. Early authors such as Aristotle did not separate taste and smell as we do now.
To Aristotle, if a sensation arose from the mouth, it was taste. If it arose from sniffing (and thus from the nose), it was olfaction. The failure to realize that olfaction is stimulated by volatiles arising from the mouth during consumption led to the classification of olfactory qualities as taste qualities (e.g., pungent). Correct separation of taste and smell simplified the lists of taste qualities but not the lists of olfactory qualities. There are many more olfactory qualities than taste qualities, and no one has yet suggested a satisfactory classification system. In general, we name odors on the basis of the substances that produce them. In fact, the olfactory system provides excellent labels for the identity of salient objects.

\section{Analysis versus Synthesis}

In the real world, most stimuli are mixtures. In the 19th century, investigators described mixtures as analytic or synthetic on the basis of whether or not the qualities in the mixture could be recognized. Playing a high note and a low note on the piano provides an example of analytic mixing: both notes can be recognized. Mixing colors on a color wheel or with colored lights provides an example of synthetic mixing: the resulting color is qualitatively distinct from its components such that the components can no longer be recognized. Although some have argued for synthetic mixing in taste (Erickson \& Covey, 1980), most investigators have concluded that taste is analytic since empirical data show that subjects can recognize the four qualities in taste mixtures (e.g., Bartoshuk, 1975). This characteristic of taste provides a clue about the function of taste. Taste appears to be tuned to specific nutrients so that an organism can detect those specific nutrients wherever they occur. For example, an animal seeking $\mathrm{NaCl}$ can detect a salty taste from a salt lick, from sea water, or from blood. Similarly, an animal could detect a bitter poison even if it were to be only one component of an otherwise sweet fruit.

On the other hand, olfaction provides both examples of analytic and synthetic mixing. McBurney (1986) gives walnut smell as an example of a synthetic mixture since the components do not smell like walnut. Yet, there are many examples of analytic olfactory mixing (e.g., the ability to smell food and the perfume of a dinner companion simultaneously; see McBurney, 1986). Cain $(1984,1987)$ has suggested that even when olfactory mixtures can be processed analytically, they may not be. He suggests that we code olfactory mixtures holistically and form odor templates in memory. Odor recognition then becomes a matter of matching the holistic perception to the template. This is a system that is beautifully suited to label the large number of food objects that an organism encounters.

\section{Hedonic Properties of Taste and Smell}

The hedonic tone of taste qualities is universally understood. In fact, taste qualities lend their value connotations to nongustatory situations. For example, "she is sweet" is understood to imply a positive personality trait, and "she is bitter" is understood to imply a negative trait. Olfactory qualities cannot be used in this same way. One 
reason for this distinction is that the affect associated with taste is present at birth (Steiner, 1977), whereas that associated with olfaction apparently must be acquired by experience (Engen, 1979, 1982).

\section{TASTES AND SMELLS OF NUTRIENTS}

\section{Macronutrients}

The macronutrients are those that provide calories: fats, proteins, and carbohydrates. Carbohydrates include starch and sugar. Fat, protein, and starch molecules present a problem to the chemical senses. The molecules consist of chains that, in many cases, are of an indeterminate length (e.g., starch). Neither taste nor smell can detect these molecules. The apparent sensations that are associated with the protein and fat that we eat consist of traces of volatiles that are present. Starch is tasteless to humans, but some forms of starch are detected by rats (Sclafani \& Mann, 1987). Sugars are also chains of molecules, but we have receptors that detect some of them. Sucrose, common table sugar, is made of glucose and fructose. Sucrose, fructose, and glucose are the sweetest of the common sugars.

\section{Micronutrients}

Micronutrients consist of vitamins and minerals. Vitamins in concentrated form have a variety of tastes and smells (mostly unpleasant); however, they are usually too dilute in food to be detected. Minerals are usually consumed in salt form. The small cations of salts are salty (i.e., lithium and sodium). The larger cations taste bitter as well as salty (see below for species differences). Small anions of salts have no taste of their own, but as anions get larger, they increasingly inhibit the taste of cations. When large enough, anions take on bitter or sweet tastes. In sum, $\mathrm{NaCl}$ produces the canonical salty taste. Other salts tend to be bitter as well as salty.

\section{Function of Taste and Smell in Directing Nutritive Behavior}

An evaluation of the tastes and smells that nutrients produce leads to the conclusion that macronutrients, except for sugars, cannot be directly sensed. Rather, they must be detected via the tastes and smells of the other substances in the food objects in which they occur. Thus, learning is necessary to attach a sensory label to fats, proteins, and starch.

Vitamins are simply too dilute to be sensed directly in foods. They too can only be detected via the tastes and smells of the food objects in which they occur. On the other hand, mineral salts can be detected by the sense of taste. However, we have only a limited ability to distinguish among cations. $\mathrm{NaCl}$ is pure salty. Other important cations (e.g., potassium, calcium) taste bitter as well as salty.

The idea of "wisdom of the body" (Davis, 1928; Richter, 1942-1943) suggests that need could be detected by the body, which sets up a craving that would motivate the organism to seek out the necessary nutrient and in- gest it. The analysis above suggests that the nutrients detected by the taste system could be regulated in this way. On the other hand, the other nutrients must be regulated by associations between their effects and the sensory labels (primarily olfactory) that accompany them in food objects.

\section{VARIATION IN SENSORY EXPERIENCE}

Some of the variability across individuals comes from our genes. Other variability comes from age, disease, or damage to the sensory organs. The examples that follow were chosen to illustrate sensory issues that are relevant to the other contributions in this symposium.

\section{PTC/PROP Genetics and Taste}

PTC (phenylthiocarbamide) tastes intensely bitter to some but nearly tasteless to others (Harris \& Kalmus, 1949). Since the discovery of this phenomenon in the 1930 s, a variety of studies have been done to elucidate the mode of inheritance of this trait as well as to determine its impact on ordinary taste experience. In recent years, a chemical relative, PROP (6- $n$-propylthiouracil), has been substituted for PTC for two reasons. PTC has an odor and PROP has essentially none (Fischer, 1967). In addition, PROP is a medication (used to suppress thyroid function in hyperthyroidism) and so toxicity data are available. PROP can be used in quantities far less than those used to produce pharmacological reactions.

PROP sensitivity is generally said to be a simple Mendelian recessive characteristic. Those who carry two recessive genes are nontasters (i.e., have very high thresholds for PROP), whereas those who carry one or both dominant genes are tasters (i.e., have low thresholds for PROP). Suprathreshold scaling of the bitterness of PROP among tasters produces variable functions. Some functions are flat, suggesting that even high PROP concentrations are only mildly bitter to these tasters. On the other hand, some functions are steeply accelerated, suggesting that high concentrations of PROP are intensely bitter to these tasters. We speculate that these differences may reflect heterozygous and homozygous tasters, respectively, but there is no definitive proof of this as yet.

Originally, this "taste blindness"' was believed to involve only a few compounds: those similar to PTC and PROP that shared a particular molecular configuration. However, more extensive testing showed that a variety of other compounds not chemically related to PTC or PROP were also involved. These included both bitter and sweet compounds that tended to be perceived as less intense to nontasters. The sweet compounds include sucrose (Gent \& Bartoshuk, 1983), the sweet taste of saccharin (Bartoshuk, 1979), glucose (Marino \& Bartoshuk, 1991), and neohesperidin dihydrochalcone (Gent \& Bartoshuk, 1983). The bitter compounds include caffeine (Hall, Bartoshuk, Cain, \& Stevens, 1975), KCl (Bartoshuk, Rifkin, Marks, \& Hooper, 1988), $\mathrm{CaCl}_{2}$ (Marino et al., 1991), and the bitter taste of saccharin (Bartoshuk, 1979).

The $\mathrm{CaCl}_{2}$ results along with earlier observations (Scott, 1946) that some rats died rather than consume casein (the 
protein in milk) led us to suspect that some concentrated milk products might taste more bitter to tasters. Studies in adults with casein and dried milk showed that some tasters report a bitter taste in these substances. Since protein molecules are too large to have a taste themselves, this bitter taste is probably the result of breaking down some of the protein into the constituent amino acids, which can have a bitter taste. Studies in adults (Marino et al., 1991) showed that some cheeses taste more bitter to tasters than to nontasters. In a study with 5- to 6-year-olds (Anliker, Bartoshuk, Ferris, \& Hooks, in press), eight foods (cheddar cheese, milk, lemonade, raw broccoli, cooked broccoli, spinach, coffee, and banana) were sampled and then rated in order of preference. The method used was that of Birch (1979). The eight foods were placed on a table. The child was asked to select his/her favorite and that item was removed. The child was then asked to select his/her favorite from the remaining seven, and so on. The average position of the cheddar cheese was 1.38 for the nontasters, 3.24 for the medium tasters, and 5.40 for the strong tasters. The impact of this sensory variation on everyday consumption is unknown.

\section{Age}

There seems to be a general belief that all sensory function starts to deteriorate with age. In the chemical senses, there is some good news and some bad news. The good news is that taste is very robust across age (Bartoshuk, Rifkin, Marks, \& Bars, 1986; Stevens, Bartoshuk, \& Cain, 1984). The bad news is that olfactory sensations do diminish with age (Stevens \& Cain, 1987). One of the most important questions concerns whether the decline in olfaction is due to age per se or to some other cause(s) that may cumulate over a lifetime. A resolution of this issue will depend on thorough studies of the factors known to affect the chemical senses.

\section{Clinical Loss of Taste and Smell}

Olfaction. Three major etiologies have been found to be associated with olfactory loss: head injury, upper respiratory infection, and nasal disease (Deems et al., 1990; Goodspeed et al., 1986). Olfactory loss from head injury is probably most often associated with fractures of the cribiform plate, the bone through which the olfactory nerve travels on its way to the brain. Olfactory loss from nasal disease is often a conductive loss. For example, polyps growing high in the nasal cavity can occlude the olfactory cleft and thereby prevent odor molecules from reaching olfactory receptors. Olfactory loss from upper respiratory infection may prove to be the most interesting of all cases. Olfactory receptors are actually the ciliated dendrites of the olfactory neurons; there is no synapse between the receptor and the neuron. This means that if a virus or toxin gains entry into the olfactory cilia, the virus or toxin can be transported up the neuron directly into the brain (e.g., Roberts, 1986). Olfactory losses associated with upper respiratory infection may reflect damage done to olfactory neurons by viruses.
Taste. Two of the three etiologies discussed above also affect taste (Bartoshuk, Catalanotto, Scott, \& Solomon, 1989). Head injury may do either peripheral or central damage to the taste system. Viruses cannot enter the taste system as they do the olfactory system because there is a synapse between the taste receptor cell and the taste neuron. However, the chorda tympani branch of the facial nerve, which carries taste from the front of the tongue to the brain, passes through the middle ear on its way to the brain. In that location, it could be susceptible to the invasion of viruses. In a sample of patients with olfactory loss associated with upper respiratory infection, taste loss was found on the front of the tongue. This suggests that otitis media might be associated with taste loss. Although this association has not been studied in recent years, it was well known in the last century (Urbantschitsch, 1876).

Olfactory loss is more common than taste loss. Why? The majority of patients that complain of taste and smell loss turn out to be describing smell loss. They are using "taste" to refer to "flavor." With smell absent or lessened, the perception of the flavor of food is certainly impaired. Once patients were given the correct distinction between taste and smell, they understood that they had suffered a smell loss. However, we found that even when patients had genuinely suffered substantial taste loss, they often failed to notice it.

In an effort to determine how much of the system would have to be damaged to affect real-world taste perception, we anesthetized parts of the taste system (Ostrum, Catalanotto, Gent, \& Bartoshuk, 1985). To our surprise, when we began by anesthetizing the chorda tympani nerve on one side of the front of the tongue, whole-mouth taste perception actually improved. This should not have been such a surprise because Halpern and Nelson (1965) had already seen a similar phenomenon in the rat. When recording from the medulla where both the chorda tympani and glossopharyngeal nerves project, anesthesia of the chorda tympani caused responses from the field of the glossopharyngeal to increase. Halpern and Nelson suggested that the increase was caused by release of inhibition. Subsequently, we anesthetized one chorda tympani nerve and tested various oral loci to determine the source of the intensification in our human subjects. As expected, the source was the glossopharyngeal nerve (Lehman, 1991).

A rare patient provided evidence that the inhibition between the nerves goes in both directions (Bartoshuk, 1990). This patient cannot taste on the front of her tongue (the damage may be the result of repeated ear infections) or on her palate (this damage is due to earlier surgery). She experiences a salty phantom that we believe is caused by scar tissue pressing on her chorda tympani. Anesthetizing her mouth with a topical anesthetic effectively anesthetizes her glossopharyngeal nerves. This anesthesia causes her salty phantom to become much saltier.

These are examples of some of the etiologies currently under study for their association with losses of taste and smell. These are not rare disorders. This suggests that 
chemosensory loss may be much more common than previously suspected.

\section{SPECIES DIFFERENCES}

Animal models are invaluable for studies of food and fluid intake; however, to extrapolate the results to humans, we must be aware of sensory differences across species. There is a considerable body of evidence supporting the similarity of taste systems among mammals. There appear to be analogues for salty, sweet, sour, and bitter tastes. However, differences across species have been suggested for salty, sweet, and bitter.

\section{Salty}

The salty taste is associated with a positively charged cation of at least the size of the lithium cation. In humans, virtually all cations have some salty taste. Lithium and sodium produce a very pure salty taste; larger cations taste bitter as well as salty. As far as has been tested, all sources of saltiness cross-adapt in human subjects (Bartoshuk \& Dember, 1988; McBurney \& Lucas, 1966; Smith \& McBurney, 1969). Amiloride, a sodium channel blocker, originally appeared to block salty tastes in human subjects (Schiffman, Lockhead, \& Mars, 1983), but later work failed to confirm this observation (Desor \& Finn, 1989).

Although these conclusions are far from certain, in some lower species, the neural data suggest the possibility of two systems for saltiness. One group of neurons seems to be specifically tuned to sodium salts (Frank, Contreras, \& Hettinger, 1983). In the hamster, these neurons are amiloride-sensitive (Hettinger \& Frank, 1987). The other group of neurons appears to respond more generally to cations. These neurons are not amiloride-sensitive. Perhaps the human has only one of these two systems.

\section{Sweet}

We have known for some time that some sweeteners have little taste to certain lower species. For example, rats like saccharin but are indifferent to dulcin. Both are sweet to the human. Aspartame is sweet to the human and the higher primates but appears to have little taste to lower species (Hellekant, Glaser, Brouwer, \& Van der Wel, 1981). Polycose is mildly sweet to humans but is avidly consumed by rats (Sclafani \& Mann, 1987).

\section{Bitter}

Bitter shows variability across species as well. Bitrex, a very strong bitter to humans, appears to have little taste to such species as the sheep.

\section{REFERENCES}

Anliker, J. A., Bartoshuk, L. M., Ferris, A. M., \& Hooks, L. D. (in press). Children's food preferences and genetic sensitivity to the bitter taste of PROP. American Journal of Clinical Nutrition.
BartoshUK, L. M. (1975). Taste mixtures: Is mixture suppression related to compression? Physiology \& Behavior, 14, 643-649.

BartoshuK, L. M. (1978). History of taste research. In E. C. Carterette \& M. P. Friedman (Eds.), Handbook of perception: Vol. VIA. Tasting and smelling (pp. 3-18). New York: Academic Press.

BARTOSHUK, L. M. (1979). Bitter taste of saccharin: Related to the genetic ability to taste the bitter substance 6-n-propylthiouracil (PROP). Science, 205, 934-935.

Bartoshuk, L. M. (1990). Psychophysical insights on taste. Science Agenda, 3, 12-13.

Bartoshuk, L. M., Catalanotto, F. A., Scott, A. E., \& SoloMON, G. M. (1989, April). Spatial taste losses associated with head trauma, upper respiratory infection, and nasal symptoms. Paper presented at the annual meeting of the Association for Chemoreception Sciences, Sarasota, FL.

Bartoshuk, L. M., \& Dember, G. (1988, April). Cross adaptation of saltiness among $\mathrm{NaCl}, \mathrm{KCl}$, and $\mathrm{NH} 4 \mathrm{Cl}$. Paper presented at the annual meeting of the Association for Chemoreception Sciences, Sarasota, FL.

Bartoshuk, L. M., Desnoyers, S., Hudson, C., Marks, L., O'Brien, M., Catalanotto, F., Gent, J., Williams, D., \& Ostrum, K. M. (1987). Tasting on localized areas. In S. Roper \& J. Atema (Eds.), Olfaction and Taste IX (pp. 166-168). New York: Annals of the New York Academy of Sciences.

Bartoshuk, L. M., Rifinin, B., Marks, L. E., Bars, P. (1986). Taste and aging. Journal of Gerontology, 41, 51-57.

Bartoshuk, L. M., Rifkin, B., MARKs, L. E., \& HoOPER, J. E. (1988). Bitterness of $\mathrm{KCl}$ and benzoate: Related to PTC/PROP. Chemical Senses, 13, 517-528.

BirCH, L. (1979). Dimensions of preschool children's food preferences. Journal of Nutrition Education, 11, 77-80.

CAIN, W. S. (1984). What we remember about odors. Perfumer \& Flavorist, 9, 17-21.

CAIN, W. S. (1987). Taste vs. smell in the organization of perceptual experience. In J. Solms, D. A. Booth, R. M. Pangborn, \& O. Raunhardt (Eds.), Food acceptance and nutrition (pp. 63-77). New York: Academic Press.

Cines, B. M., \& Rozin, P. (1982). Some aspects of the liking for hot coffee and coffee flavor. Appetite, 3, 23-34.

DAVIS, C. M. (1928). Self selection of diet by newly weaned infants: An experimental study. American Journal of Diseases of Children, 36, 651-679.

Deems, D. A., Doty, R. L., Settle, R. G., Moore-Gillon, V., Shaman, P., Mester, A. F., Kimmelman, C. P., Brightman, V. J., \& SNOw, J. S. (in press). Smell and taste disorders: A study of 750 patients from the University of Pennsylvania Smell and Taste Center. Otolaryngology-Head \& Neck Surgery.

DESOR, J. A., \& FINN, J. (1989). Effects of amiloride on salt taste in humans. Chemical Senses, 14, 793-803.

ENGEN, T. (1979). The origin of preferences in taste and smell. In J. H. A. Kroeze (Ed.), Preference behaviour and chemoreception (pp. 263-273). London: IRL.

ENGEN, T. (1982). The perception of odors. Orlando, FL: Academic Press.

ERICKSON, R. P., \& Covey, E. (1980). On the singularity of taste sensations: What is a taste primary? Physiology \& Behavior, 25, 527-533.

FISCHER, R. (1967). Gustatory, behavioral and pharmacological manifestations of chemoreception in man. In G. Ohloff \& A. F. Thomas (Eds.), Gustation and olfaction (pp. 61-81). New York: Academic Press.

Frank, M. E., Contreras, J., \& Hettinger, T. P. (1983). Nerve fibers sensitive to ionic taste stimuli in chorda tympani of the rat. Jour. nal of Neurophysiology, 50, 941-960.

Gent, J. F., \& Bartoshuk, L. M. (1983). Sweetness of sucrose, neohesperidin dihydrochalcone and saccharin is related to genetic ability to taste the bitter substance 6- $n$-propylthiouracil. Chemical Senses, 7, 265-272.

Goodspeed, R. B., Catalanotto, F. A., Gent, J. F., Cain, W. S., BartoshuK, L. M., Leonard, G., \& Donaldson, J. O. (1986). Clin- 
ical characteristics of patients with taste and smell disorders. In H. L. Meiselman \& R. S. Rivlin (Eds.), Clinical measurement of taste and smell (pp. 451-466). New York: Macmillan.

GreEN, B. G. (1977). Localization of thermal sensation: An illusion and synthetic heat. Perception \& Psychophysics, 22, 331-337.

GREEN, L., \& BARTOSHUK, L. M. (1991). [Localization illusions in taste]. Unpublished raw data.

Hall, M. J., Bartoshuk, L. M., Cain, W. S., \& Stevens, J. C. (1975). PTC taste blindness and the taste of caffeine. Nature, 253, 442-443.

HalPeRN, B. P. , Nelson, L. M. (1965). Bulbar gustatory responses to anterior and to posterior tongue stimulation in the rat. American Journal of Physiology, 209, 105-110.

HaRRIS, H., KalmUS, H. (1949). The measurement of taste sensitivity to phenylthiourea (P.T.C.). Annals of Eugenics, 15, 24-31.

Hellekant, G., Glaser, D., Brouwer, J., Van der Wel, H. (1981). Gustatory responses in three prosimian and two simian primate species (Tupapia glis, Nycticebus, Galago senegalensis, Callithrix jacchus jacchus and Saguinus midas niger) to six sweeteners and miraculin and their phylogenetic implications. Chemical Senses, 6, 165-173.

Hettinger, T. P., \& Frank, M. E. (1987, April). Specificity of amiloride inhibition of taste responses in single fibers of the hamster chorda tympani nerve. Paper presented at the annual meeting of the Association for Chemoreception Sciences, Sarasota, FL.

HoRN, W. (1825). Uber den Geschmackssin des Menschen. Heidelberg: Karl Groos.

LEHMAN, C. (1991). The effect of anesthesia of the chorda tympani nerve on taste perception in humans. Unpublished doctoral dissertation, Yale University, New Haven, CT.

Marino, S., \& Bartoshuk, L. M. (1991). [Effects of PROP status on the tastes of sweeteners]. Unpublished raw data.

Marino, S., Bartoshuk, L. M., Monaco, J., Anliker, J. A., ReED, D., \& DEsnoyers, S. (1991). PTC/PROP and the tastes of milk products. Paper to be presented at the Thirteenth Annual Meeting of the Association for Chemoreception Sciences, Sarasota, FL, April 17-21, 1991.

MCBURNEY, D. H. (1986). Taste, smell, and flavor terminology: Taking the confusion out of fusion. In H. L. Meiselman \& R. S. Rivlin (Eds.), Clinical measurement of taste and smell (pp. 117-125). New York: Macmillan
MCBuRNey, D. H., LuCAs, J. A. (1966). Gustatory cross adaptation between salts. Psychonomic Science, 4, 301-302.

Ostrum, K. M., Catalanotto, F. A., Gent, J. F., Bartoshuk, L. M. (1985). Effects of oral sensory field loss of taste scaling ability. Chemical Senses, 10, 459.

RichteR, C. P. (1942-1943). Total self regulatory functions in animals and human beings. Harvey Lecture Series, 38, 63-103.

Roserts, E. (1986). Alzheimer's disease may begin in the nose and may be caused by aluminocilicates. Neurobiology of Aging, 7, 561-567.

Rozin, P., \& KENNEL, K. (1983). Acquired preferences for piquant foods by chimpanzees. Appetite, 4, 69-77.

Rozin, P., Schiller, D. (1980). The nature and acquisition of a preference for chili pepper by humans. Motivation \& Emotion, 4, $77-101$.

SChiffman, S., Lockhead, E., Mars, F. (1983). Amiloride reduces the taste intensity of $\mathrm{Na}^{+}$and $\mathrm{Li}^{+}$salts and sweeteners. Proceedings of the National Academy of Sciences, 80, 6136-6140.

SClafani, A., MANN, S. (1987). Carbohydrate taste preferences in rats: Glucose, sucrose, maltose, fructose and polycose compared. Physiology \& Behavior, 40, 563-568.

ScotT, E. M. (1946). Self selection of diet: I. Selection of purified components. Journal of Nutrition, 31, 397-406.

SMITH, D. V., \& McBURNEY, D. H. (1969). Gustatory cross-adaptation: Does a single mechanism code the salty taste? Journal of Experimental Psychology, 80, 101-105.

STEINER, J. (1977). Facial expressions of the neonate infant indicating the hedonics of food-related chemical stimuli. In J. M. Weiffenbach (Ed.), Taste and development: The genesis of sweet preference (pp. 173-188). Bethesda, MD: U.S. Department of Health, Education, and Welfare.

Stevens, J. C., Bartoshuk, L. M., Cain, W. S. (1984). Chemical senses and aging: Taste versus smell. Chemical Senses, 9, 167-179.

Stevens, J. C., \& Cain, W. S. (1987). Old-age deficits in the sense of smell as gauged by thresholds, magnitude matching, and odor identification. Psychology \& Aging, 2, 36-42.

Todrank, J., \& Bartoshuk, L. M. (1991). A taste illusion: Taste sensation localized by touch. Manuscript submitted for publication.

URBANTSCHITSCH, V. (1876). Beobachtungen uber Anomalien des Geschmacks der Tastempfindungen und der Speichelsecretion in Folge von Erkrankungen der Paukenhohle. Stuttgart: Verlag von Ferdinand Enke. 